\title{
Neurosteroids and the Nervous System: From Physiology to Pathology
}

\section{Farideh Talebi ${ }^{1,2}$, Farshid Noorbakhsh ${ }^{2 *}$}

${ }^{1}$ Shefa Neuroscience Research Center, Khatam Alanbia Hospital, Tehran, Iran

${ }^{2}$ Department of Immunology, School of Medicine, Tehran University of Medical Sciences, Tehran, Iran

\section{A BSTRACT}

Introduction: Discovering the enzymes involved in steroid biosynthesis in the central nervous system and the ability of neurons and glial cells to produce steroids is one of the major findings of neurobiology over the last two decades. Unlike classical steroids, these neurosteroids influence neuronal function through direct interactions with neurotransmitter receptors at the cell surface. Conclusion: Extensive studies have shown diverse physiological and pharmacological effects for these compounds. Moreover, neurosteroids have been shown to be involved in different pathological procedures, including neurodegenerative and neuro inflammatory disorders as well as neuropsychiatric diseases. Herein, we will review different aspects of neurosteroid biosynthesis and functions as well as their involvement in the pathogenesis of brain diseases.

* Corresponding Author: Farshid Noorbakhsh

E-mail:f-noorbakhsh@tums.ac.ir 


\title{
نورواستروئيدها و سيستم عصبى: از فيزيولوزى تا پاتولوزى
}

\author{
فريده طالبى “"، فرشيد نوربخش"ه \\ 'مركز تحقيقات علوم اعصاب شفا، بيمارستان خاتم الانبياء، تهران، ايران \\ تكروه ايمونولوزى، دانشكده يزشكى، دانشعاه علوم يزشكى تهران، تهران، ايران
}

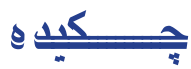

مقدمه: كشف آنزيمهاى درگير در بيوسنتز استروئيد در سيستم عصبى مركزى و توانايى نورونها

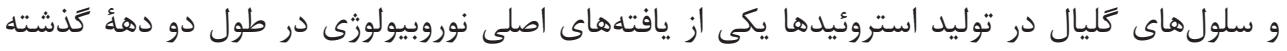

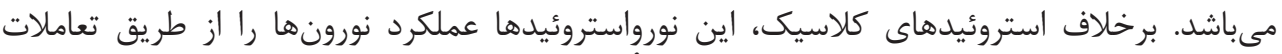

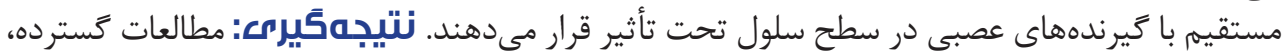

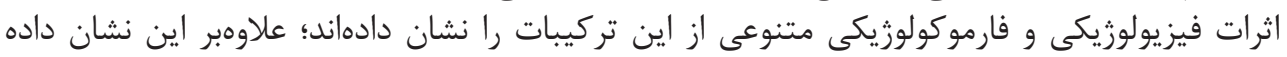

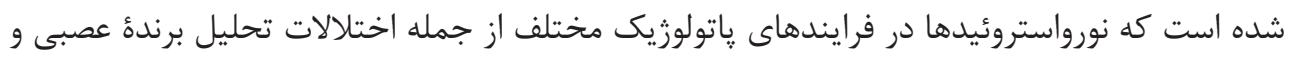

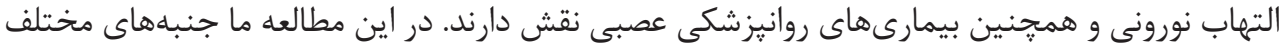

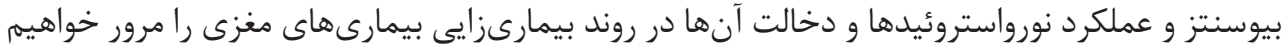

ا (. عوامل ناقلين عصبى r. r.

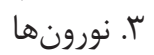

$$
\text { " نويسنده مسئول: فرشيد نوربخش }
$$


از جمله يروزسترون PREG

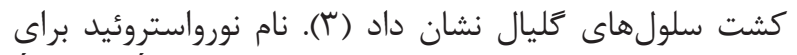

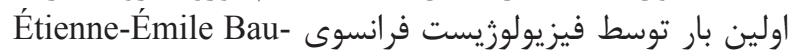

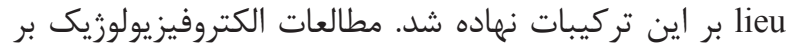

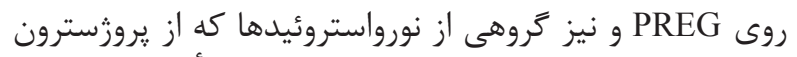

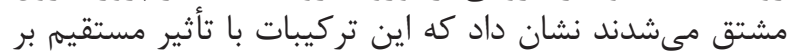

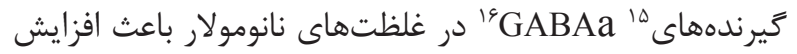

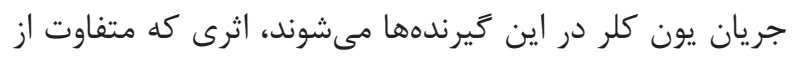

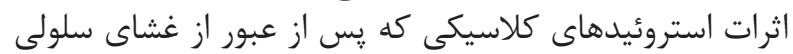

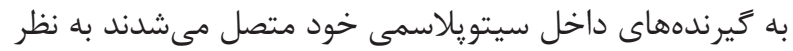

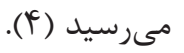

مطالعات الكتروفيزيولوزيك بر روى DHEA نقش آنتاكونيستى (الني

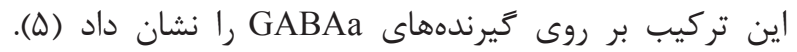

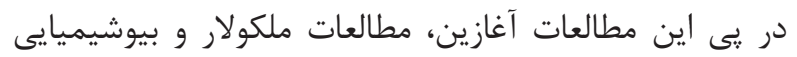

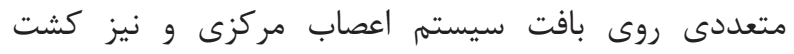

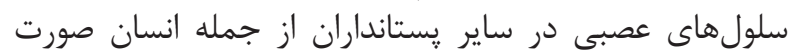

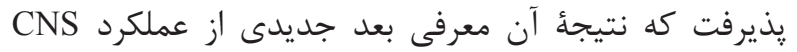

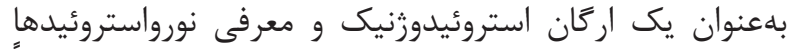

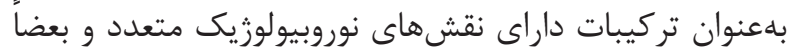

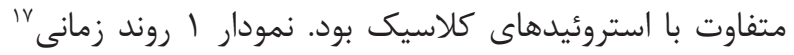

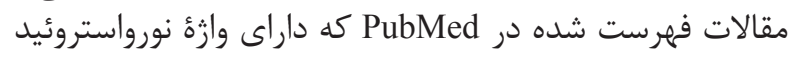

در عنوان يا جكيده مى باشند ران رانشان مى دهد (نمودار ().

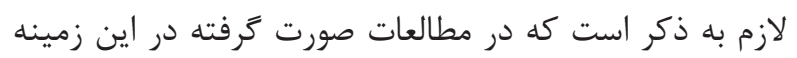

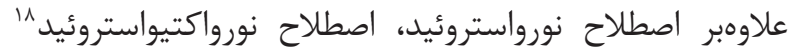

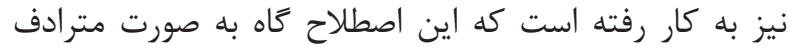

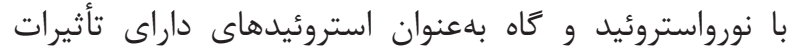

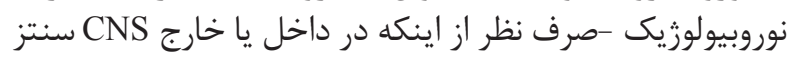

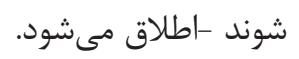

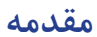

نورواستروئيدها به استروئيدهاى سنتز شده در داخل سيستم

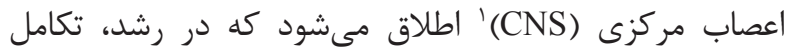

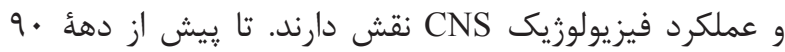

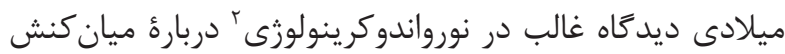

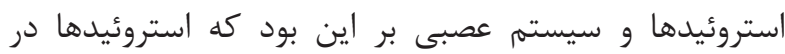

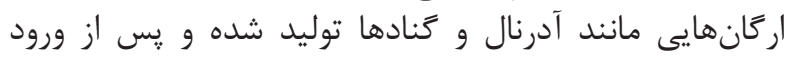

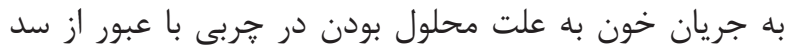

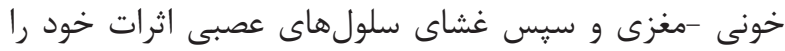

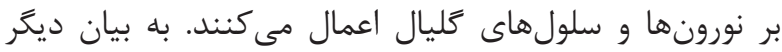

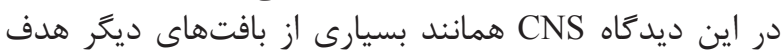

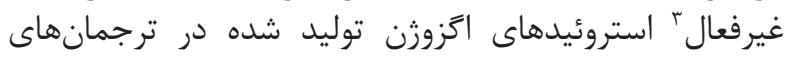
استروئيدوزنيك" به شمار مىرفتئ.

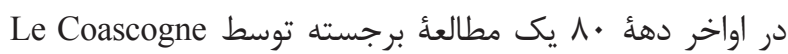

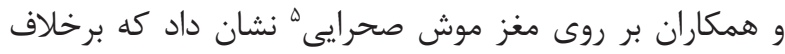

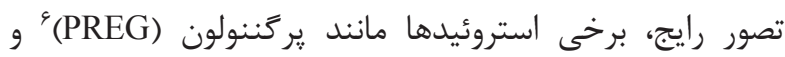

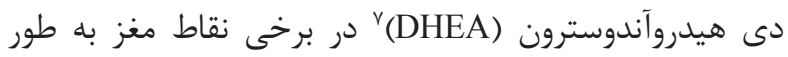

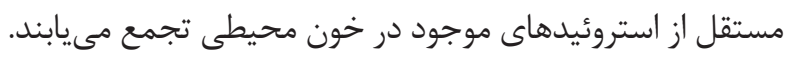

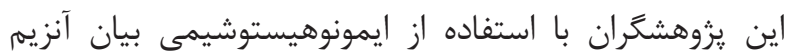

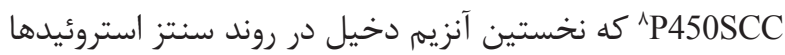

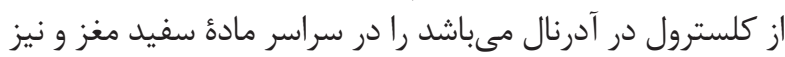

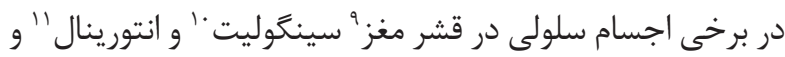
نيز در پيياز بويايى "ا در مغز موش صحر دايى نشان دادند (1).

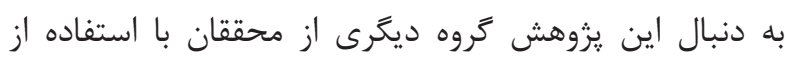

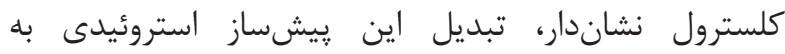
PREG

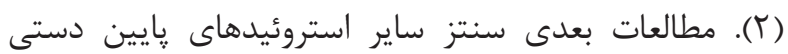

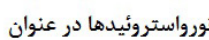

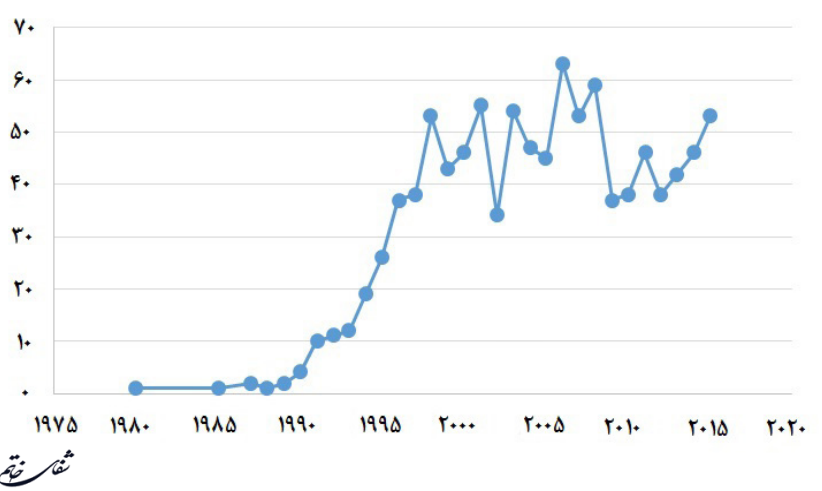

نورواستروئيدها در عنوان اخلاصه مقاله

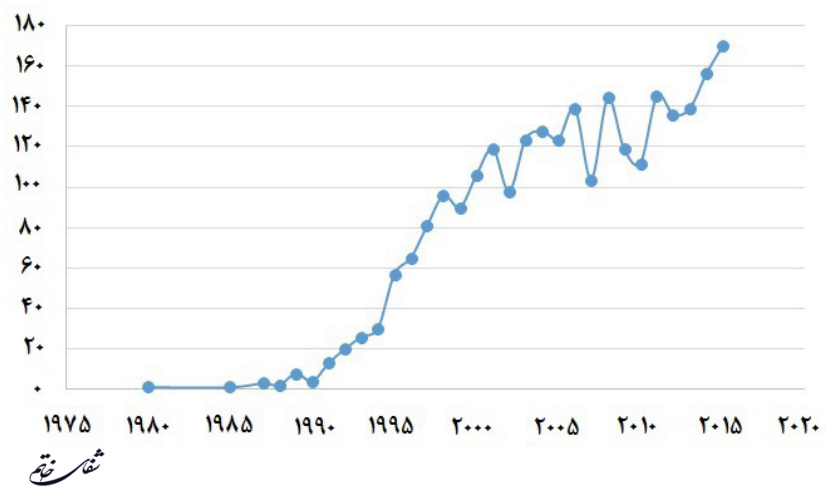
نمودار ا- روند زمانى مقالات فهر ست شده در PubMed كه داراى وارئ نورواستروئيد در عنوان يا حكيده مىباشند (منبع: PubMed).

${ }^{1}$ Central nervous system

${ }^{2}$ Neuroendocrinology

${ }^{3}$ Passive target

${ }^{4}$ Steroidogenic

${ }^{5}$ Rat

${ }^{6}$ Pregnenolone

${ }^{7}$ Dehydroepiandrosterone

${ }^{8}$ Side chain cleavage

${ }^{9}$ Cortex

\footnotetext{
${ }^{10}$ Cingulate

${ }^{11}$ Enthorhinal

${ }^{12}$ Olfactory bulb

${ }^{13}$ Oligodendrocytes

${ }^{14}$ Progesterone

${ }^{15}$ Receptors

${ }^{16}$ gamma-Aminobutyric acid A

${ }^{17}$ Timeline

${ }^{18}$ Neuroactive steroid
} 


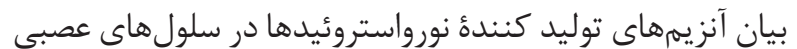

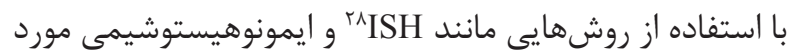

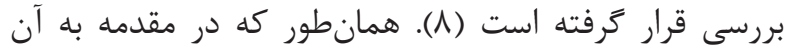

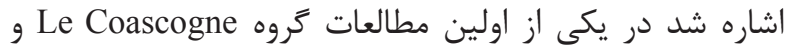
همكاران با استفاده از ايمونوهيستوشيمى ازئ بيان آنزيم د450SCC

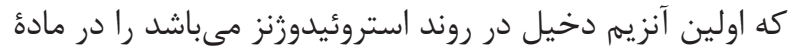

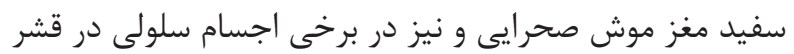

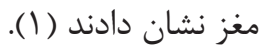
در يى اين مطالعه، Mellon و همكاران نيز بيان mRNA آنزيم

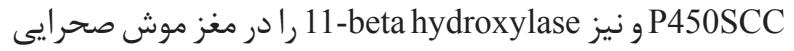
و در كشت مخلوط سلولهاى كليال و سلولهاى آستروسيتى

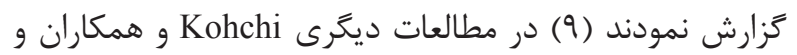
نيز Saane و همكاران علاوه بر بيان آنزيم د450SCC)

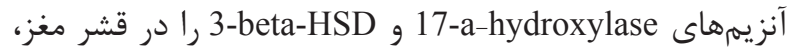
مخجه و نخاع موش صحرايى و نيز در ماده سفيد

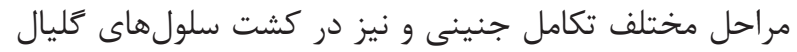

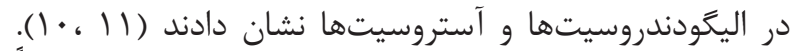

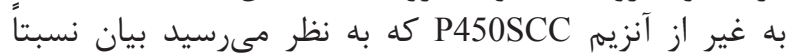

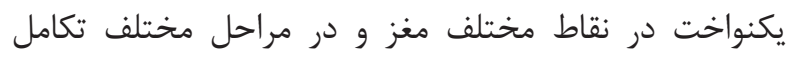

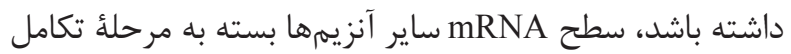

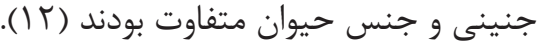

مطالعات بيشتر حضور تمام آنزيمهاى سنتز كننده نورواستروئيدها

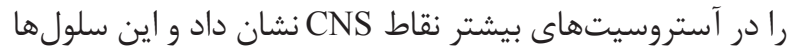
را بهعنوان منشأ اصلى بيوسنتز نورواستروئيدها معرفى نمود.

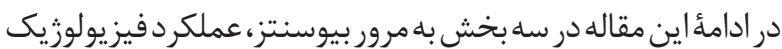

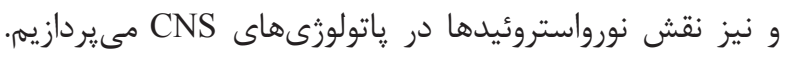

$$
\text { ا- بيوسنتز و انواع نورواستروئيدها }
$$

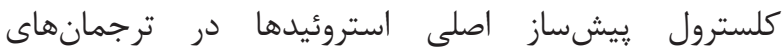

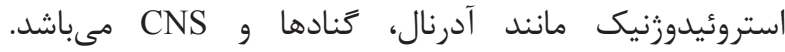

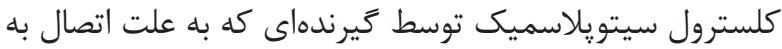

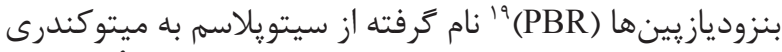

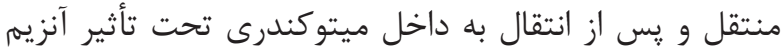

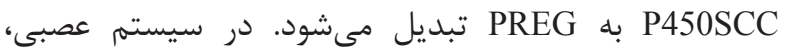

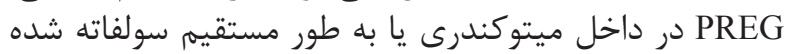

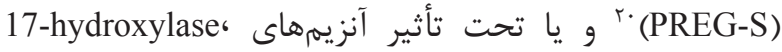
3beta-HSD

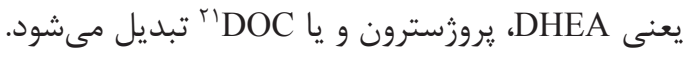
همانطور كه در نمودار r به صورت شماتيك نمايش داده شده

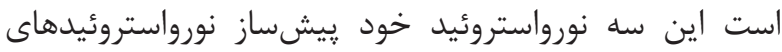
ديخرى از جمله TH Androstendione و مى وباشند. همان طور كه در ادامه به آن اشاره خواهد شد ماشين كامل سنتز

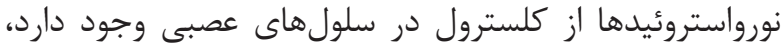

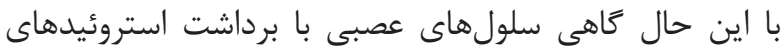

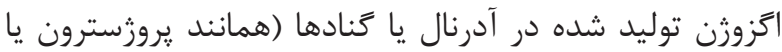
(DHEA

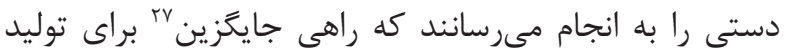
نورواستروئيدها (بهجاى سنتز از كلسترول) به شمار مىرود.

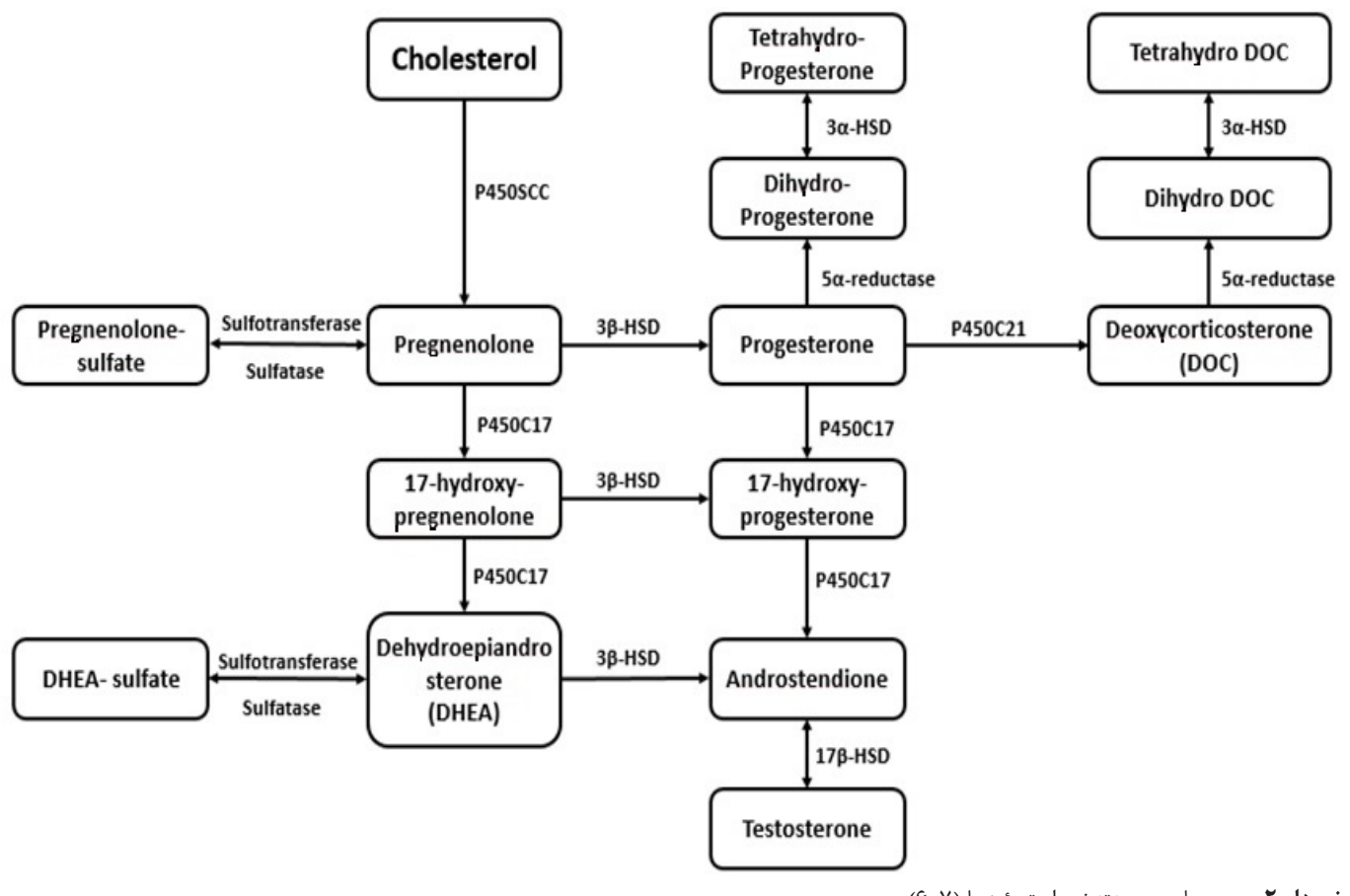

نمودار Y- مسيرهاى بيوسنتز نورواستروئيدها ( ، ،).

\footnotetext{
${ }^{19}$ Peripheral benzodiazepine receptor

${ }^{20}$ Pregnenolone- sulfate

${ }^{21}$ Deoxycorticoesterone

22 Dehydroepiandrosterone-sulfate

${ }^{23}$ Dihydro-progesterone
}
${ }^{24}$ Tetrahydro-progesterone
${ }^{25}$ Allopregnanolone ( $3 \alpha 5 \alpha-$ THP)
${ }^{26}$ Tetrahydro-deoxycorticosterone
${ }^{27}$ Alternative
${ }^{28}$ In situ hybridization 
كزارشهاى مربوط به تأثير نورواستروئيدها در بهبود روندهاى

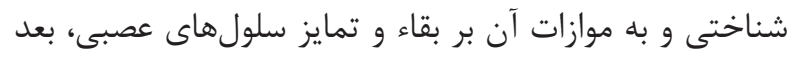

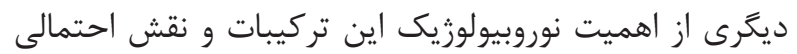

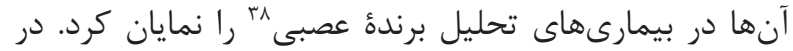

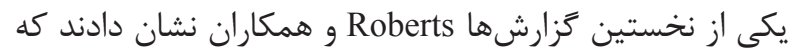
تزريق داخل بطنى إنى

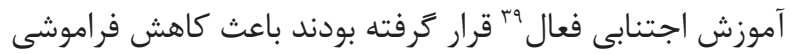

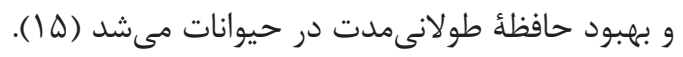

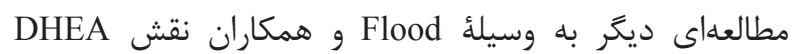

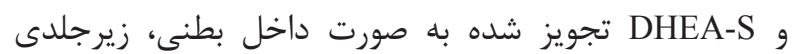

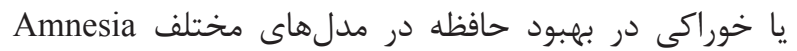

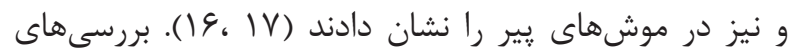

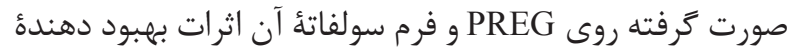

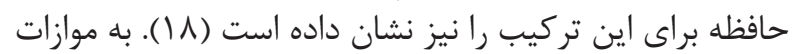

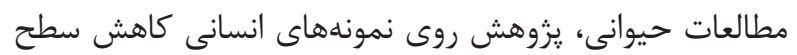

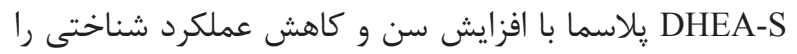

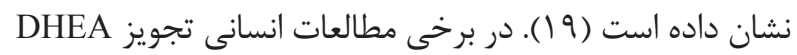

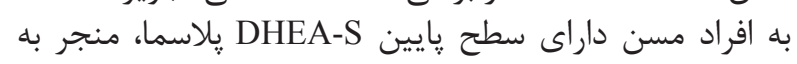

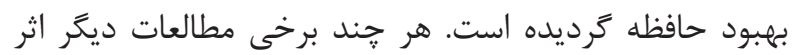
قابل ملاحظهاى را كزارش نكردهاند (• (T).

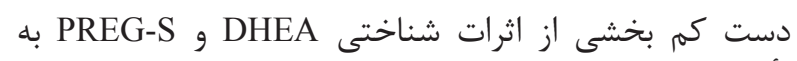

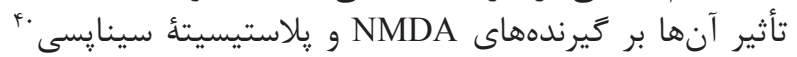

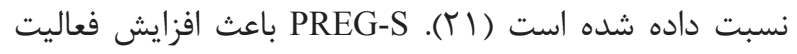

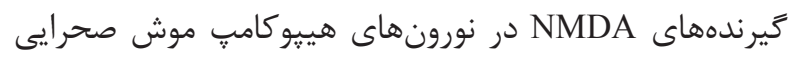

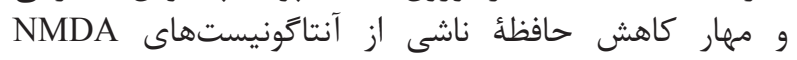

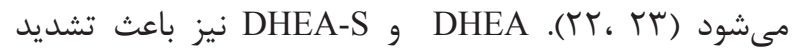

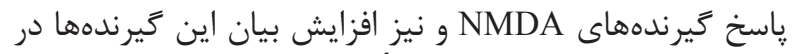

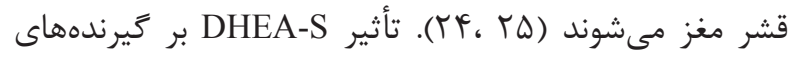

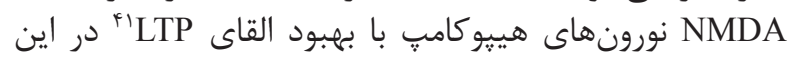

$$
\text { نورونها همراه بوده است (צ' (Y). }
$$

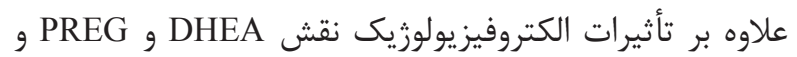

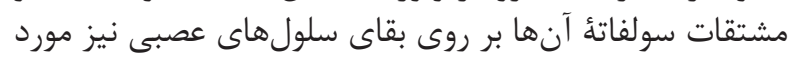

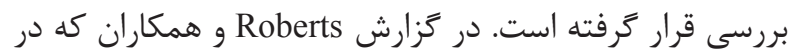

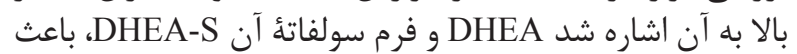

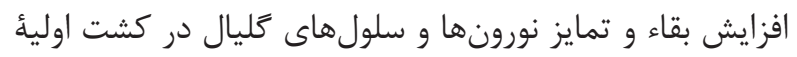

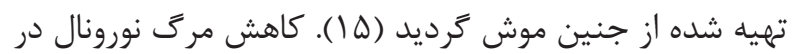

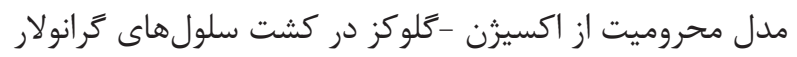

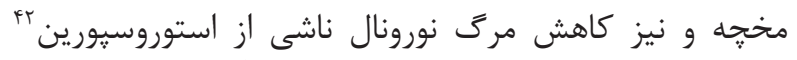

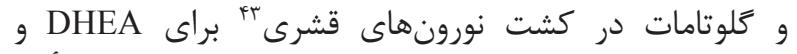

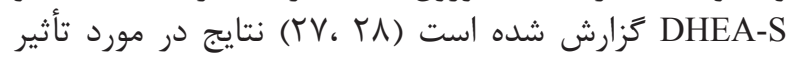
PREG-S و PREG در كاهش مرى سلولى در كشت نورونهاى قشرى مؤثر هرد

${ }^{29}$ Pyramidal

${ }^{30}$ Transcription factor

${ }^{31}$ Steroid-responsive genes

${ }^{32}$ Neurotransmitter

${ }^{33} \mathrm{~N}$-methyl-D-aspartate

${ }^{34}$ Androstendiol

${ }^{35}$ Allosteric

${ }^{36}$ Antiepileptic
توليد نورواستروئيدهاى نورونال نيز در برخى نورونها از جمله

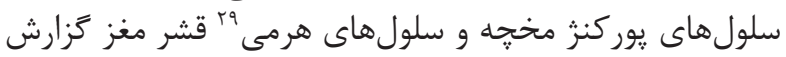

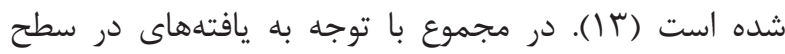
mRNA

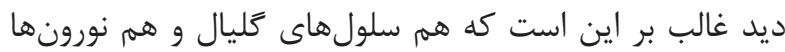

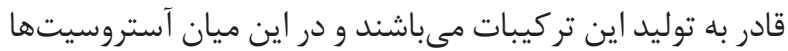

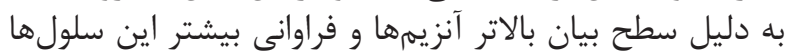
نقش غالب را در توليد اين تركيبات دارا مئرياشند.

Y - نحوه عملكرد نورواستروئيدها (Mechanism of action) استروئيدهاى كلاسيك يس از عبور از غشاى سلولها به كيرندهاى

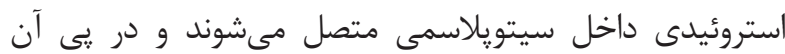

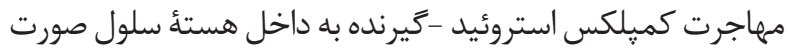

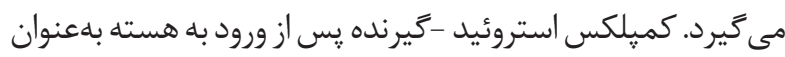

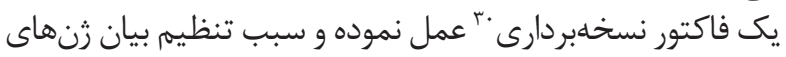

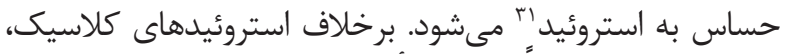

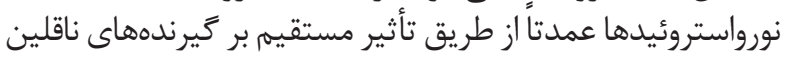

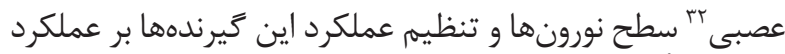

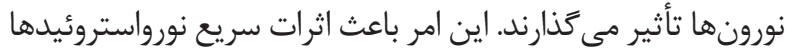
بر عملكرد سيستم عصبى مى تشود.

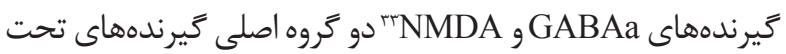

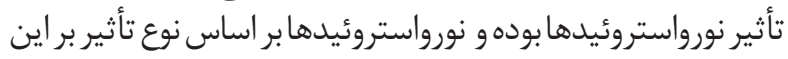

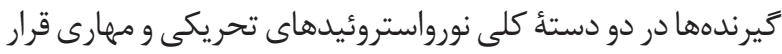

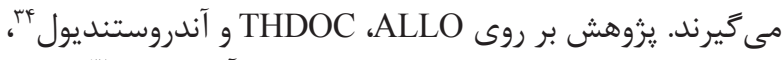

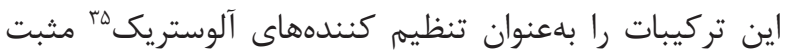

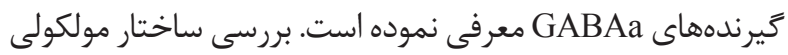

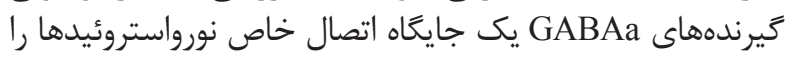

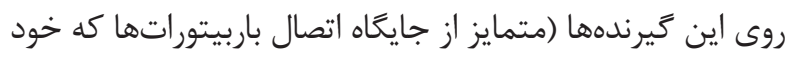

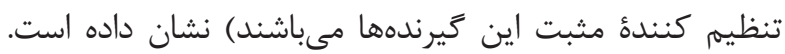

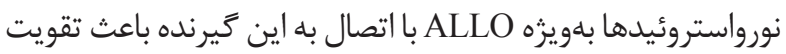
اثرات GABA و افزايش جريان يونهاى كلر از كانال GABAa

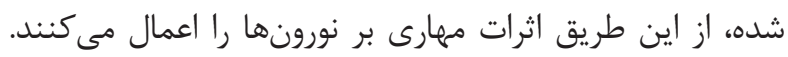

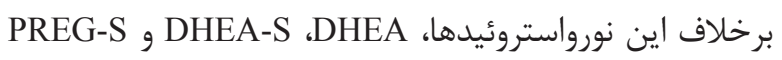

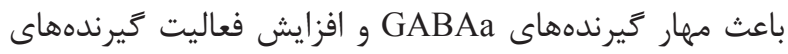

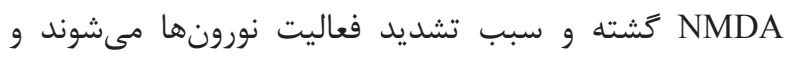

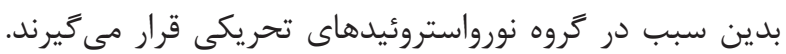

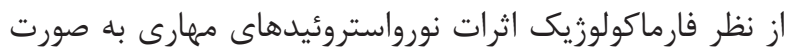

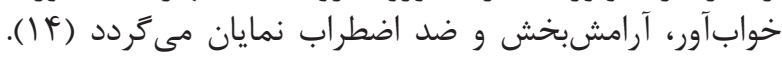

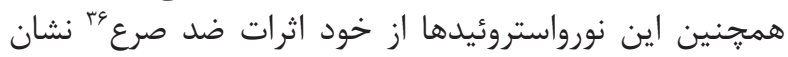

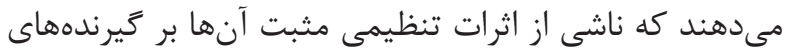
GABAa

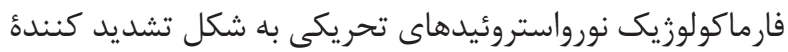

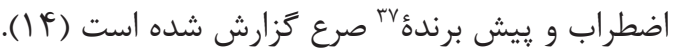

\footnotetext{
${ }^{37}$ Proconvulsant

${ }^{38}$ Neurodegenerative

${ }^{39}$ Active avoidance training

${ }^{40}$ Synaptic plasticity

${ }^{41}$ Long-term potentiation

${ }^{42}$ Staurosporine

${ }^{43}$ Cortical
} 
باعث تخريب ميلين و آسيب آكسونى له ميشود. نقش احتمالى مئى

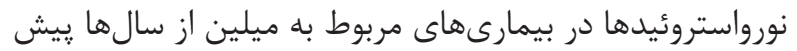

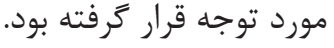

در يكى از نخستين مطالعات بر روى ارتباط نورواستروئيدها

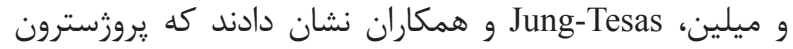

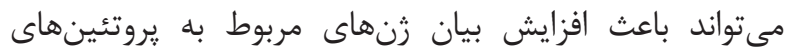

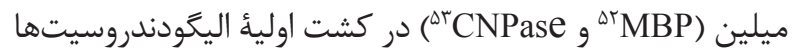

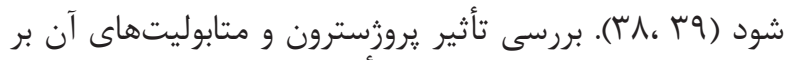

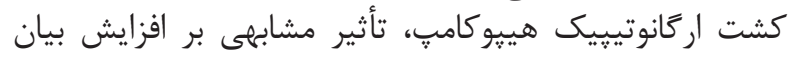

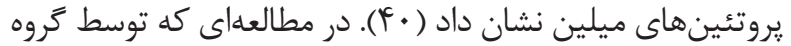

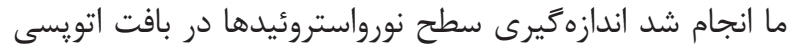

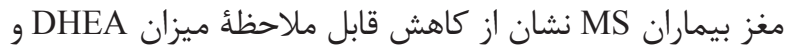

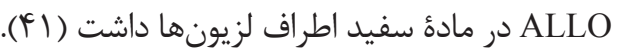

با اين حال سطح PREG كه بيشساز اصلى نورواستروئيدها به

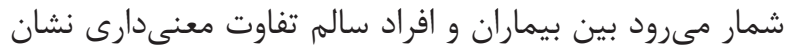

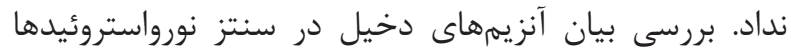
نشان از كاهش بيان 3-alpha-reductase

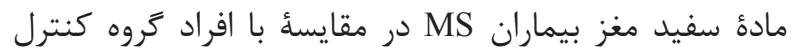

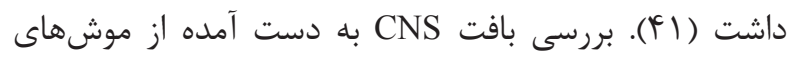

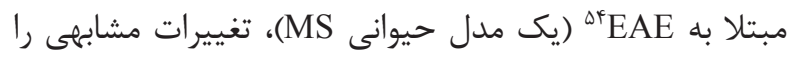

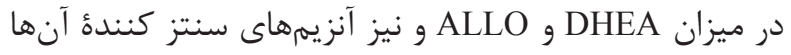

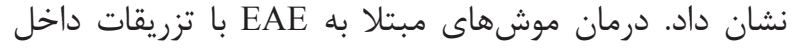

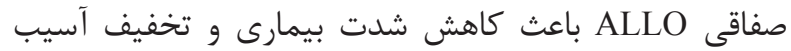

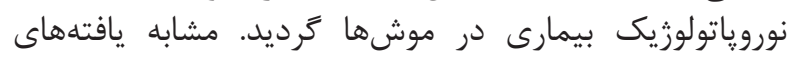

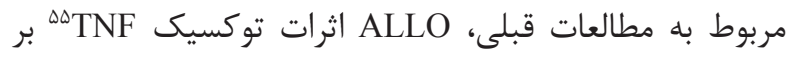

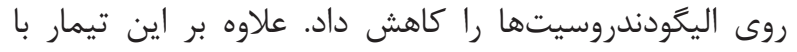

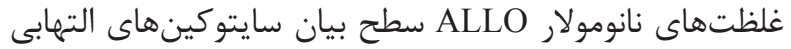

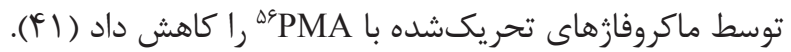

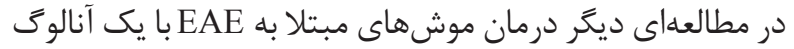

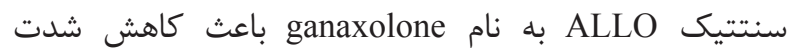

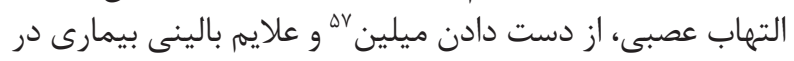

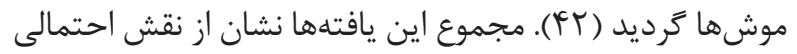

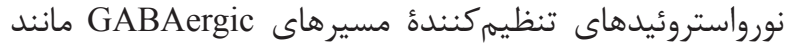

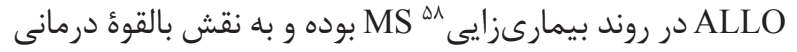
اين تركيب اشاره مى كنند (بأ)

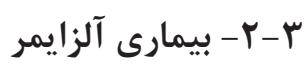

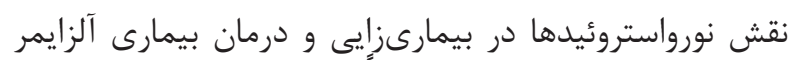

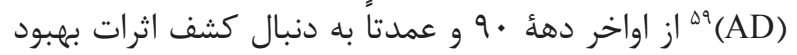

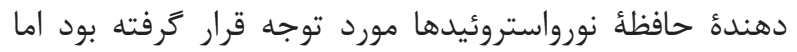

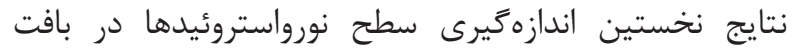

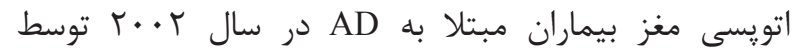
و همكاران كزارش شد. اندازهخيرى سطح PREG-S ،PREG

\footnotetext{
${ }^{44}$ Neuroprotective

${ }^{45}$ NTERA2

${ }^{46}$ Neuroinflammation

${ }^{47}$ Multiple sclerosis

${ }^{48}$ Tolerances

${ }^{49}$ Autoreactive

${ }^{50}$ Infiltration

${ }^{51}$ Axonal
}

بوده است. مطالعات بر روى PREG-S Fاه اثرات افزايشدهندة

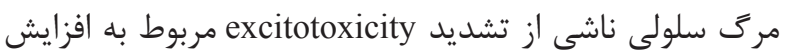

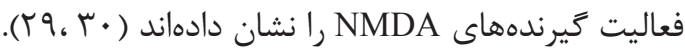

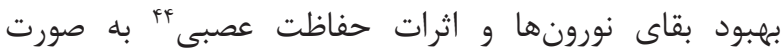

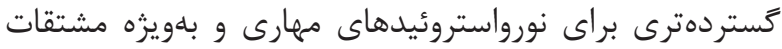

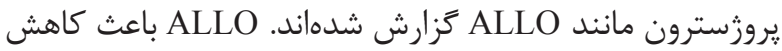

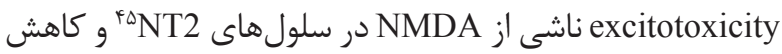

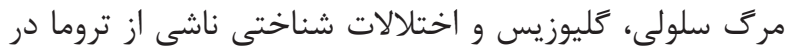

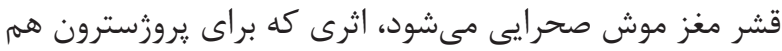

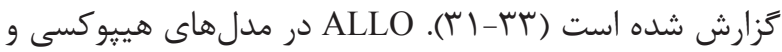

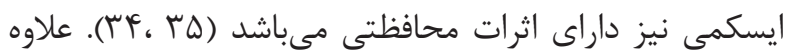

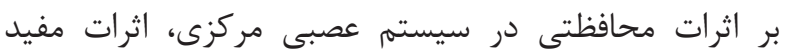

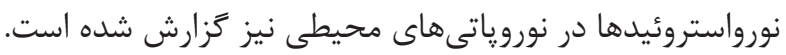

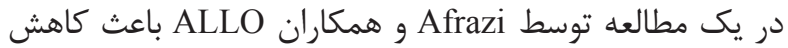

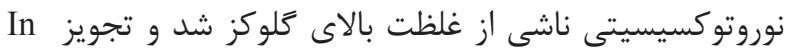
vivo

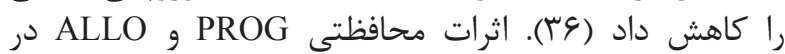

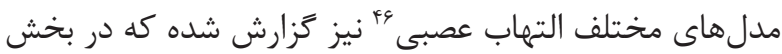

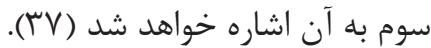

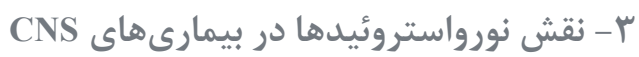
يافتههاى فراوان در مورد نقش نورواستروئيدها در تنظيم فعاليت

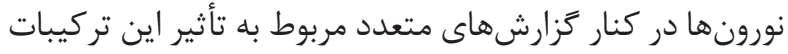

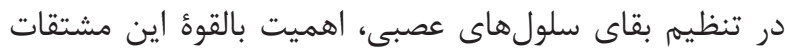

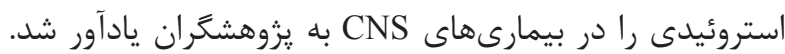

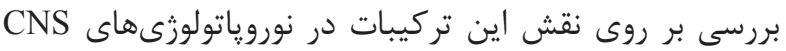

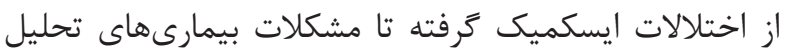

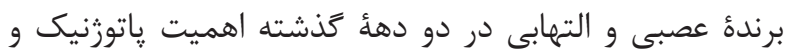

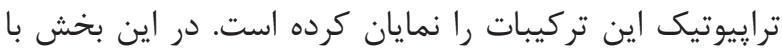

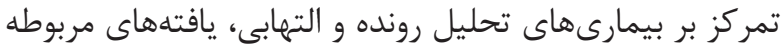
را به طور مختصر مرور خواهيم كرد.

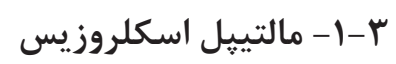

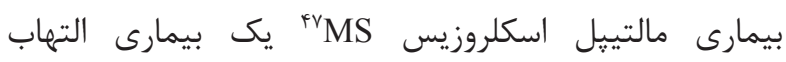

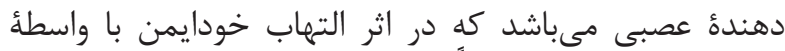

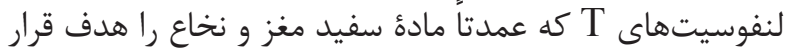

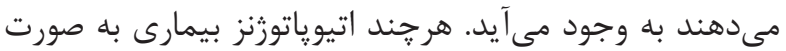

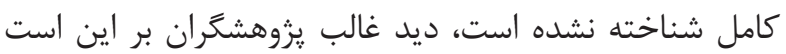

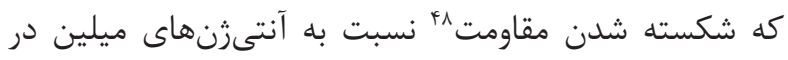

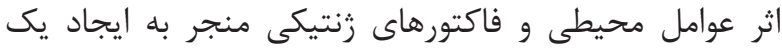

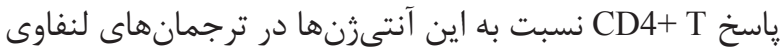

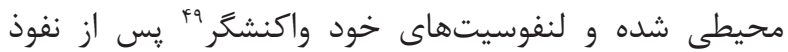

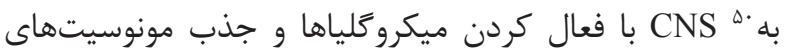

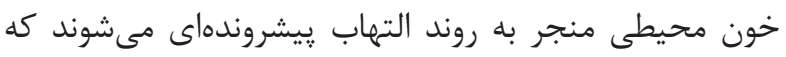

\footnotetext{
${ }^{52}$ Myelin basic protein

${ }^{53}$ 2',3'-cyclic nucleotide 3'-phosphodiesterase

${ }^{54}$ Experimental autoimmune encephalomyelitis

${ }^{55}$ Tumor necrosis factor

${ }^{56}$ Phorbol myristate acetate

${ }^{57}$ Demyelination

${ }^{58}$ Pathogenesis

${ }^{59}$ Alzheimer's disease
} 
كسترده نورونهاى دوريامينرزيك جسهم سياه (SN)

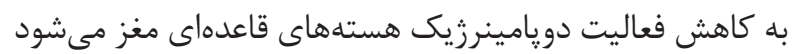

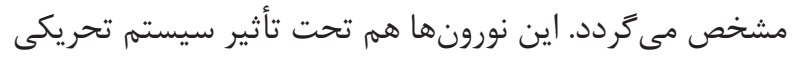
كلوتامرزيك و هم تحت اثر سيستم مهرد

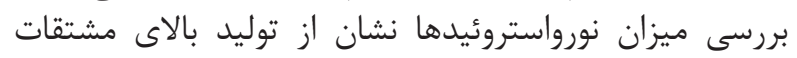

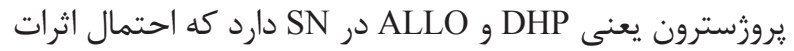
تنظيمى اين تركيبات بر بيامرسانى

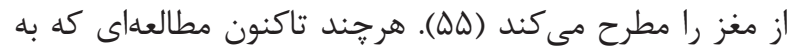

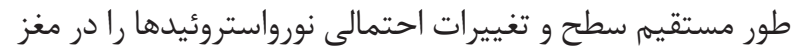

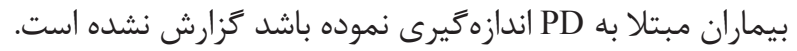

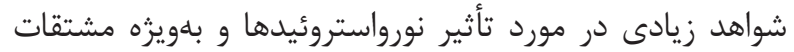

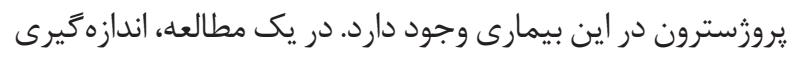

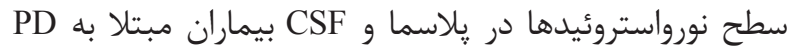
نشان از كاهش قابلملاحظة سطح DHP و

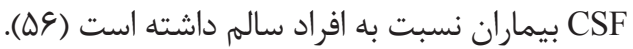

بررسى سطح mRNA كد كننده آنزيمهاى دخيل در سنتز

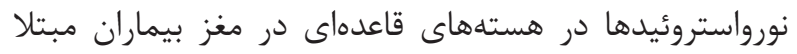

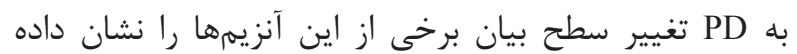

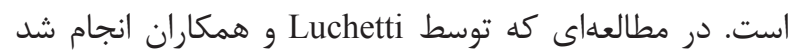

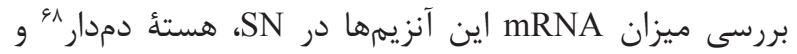
يوتامن نشان از كاهش سطح

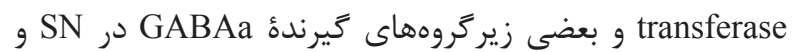
برعكس افزايش ميزان 3-alpha-HSD در هستو زئه دمدار داش داشت (DV) از تغييرات نورواستروئيدها را در اين بيمارى نشان نشان داني داده است.

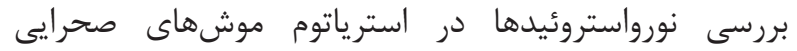
نشان داد موشهايى كه

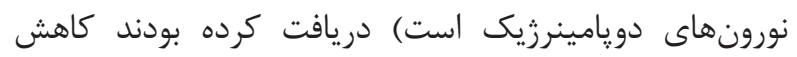

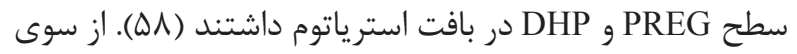

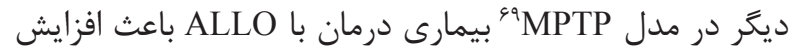

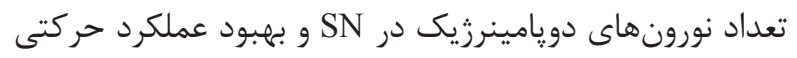

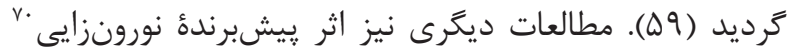

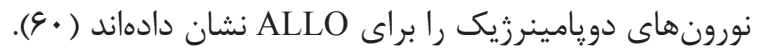

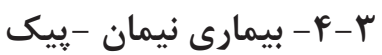

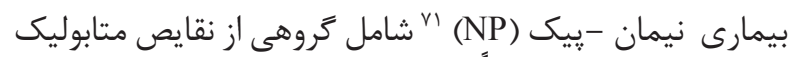

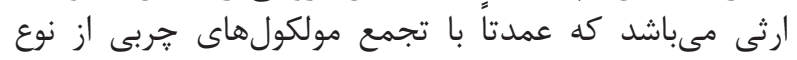

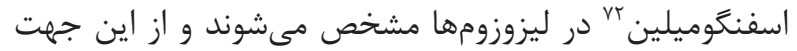

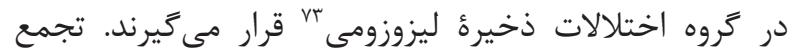

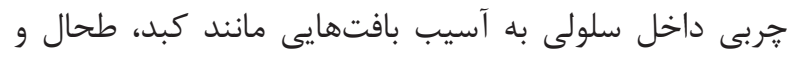
CNS

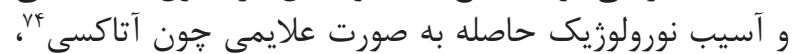

${ }^{60}$ Cerebrospinal fluid

${ }^{61}$ Pre frontal cortex

${ }^{62}$ Temporal cortex

${ }^{63}$ Bio marker

${ }^{64}$ Oxidative stress

${ }^{65}$ Parkinson's disease

${ }^{66}$ Substantia Nigra

${ }^{67}$ Signaling
نقاط مختلف مغز توسط اين يزوهشگران نشانگر كاهش سطح

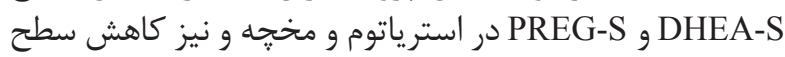

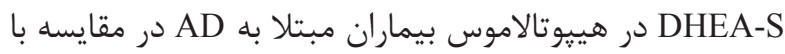

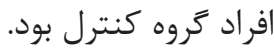

جالب اينكه در بيماران AD يك همبستخى منفى بين ميزان يلاكهاى بتا -آميلوئيد و سطح

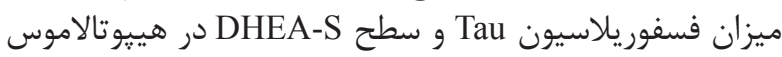

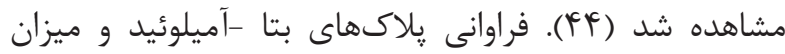

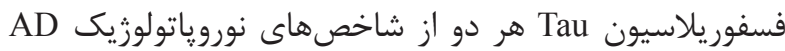

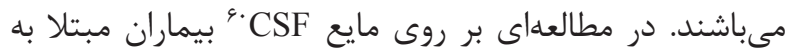

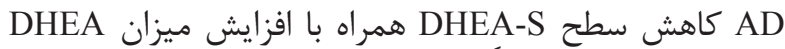
كزارش شد كه احتمالاً ناشى از نقص سولفاته شدن

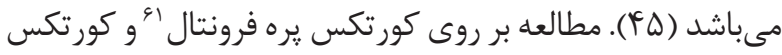

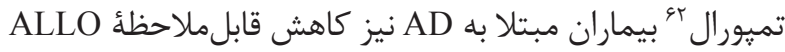

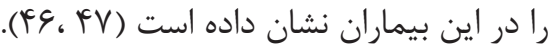

در كنار نقش بالقوه ياتوزنيك نورواستروئيدها در AD، اندازهخيرى

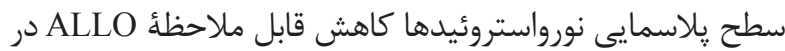
بيماران AD را نشان داده است كه احتمال استفاده از اين سطوح

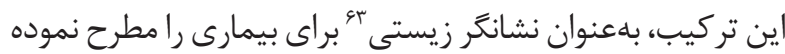

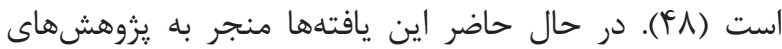

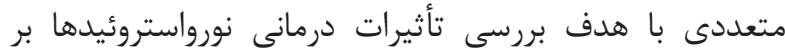

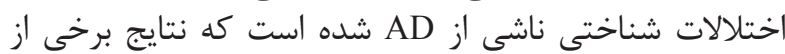

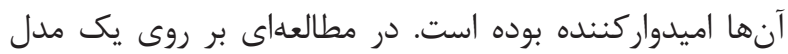

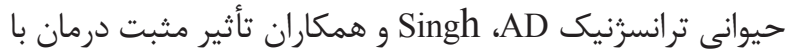
ALLO

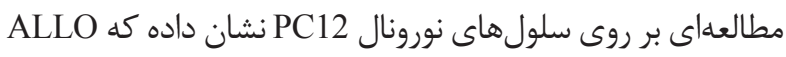

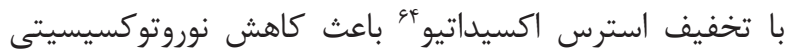
يِيتيد Ab25-35 روى اين سلول ها مىشود ( • (ه).

علىرغم اثرات مثبت گزارش شده، تجويز طولانىمدت ALLO

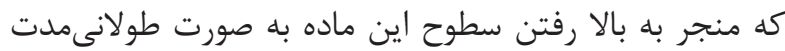

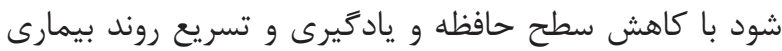

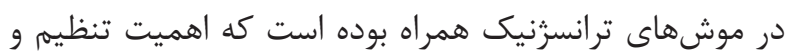

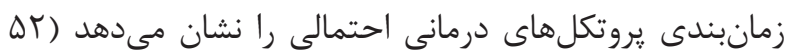

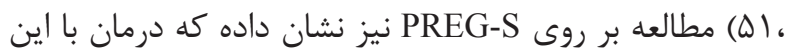

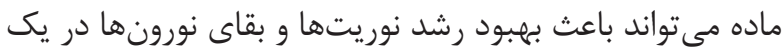

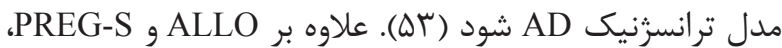

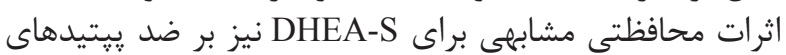

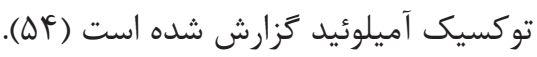

\section{r-r - بيمارى یار كينسون}

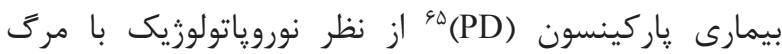




\section{نتيجه}

كشف قابليت توليد استروئيدها توسط CNS، توانايى اين تركيبات

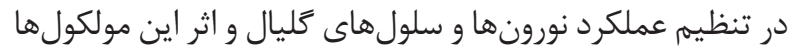

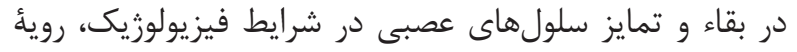

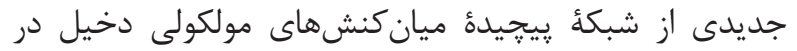

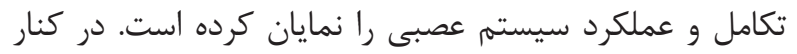

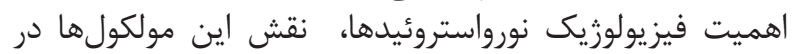

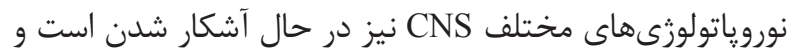

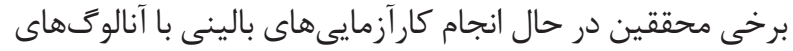

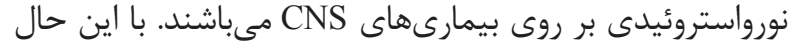

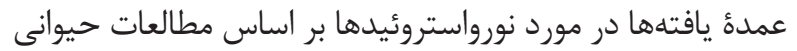

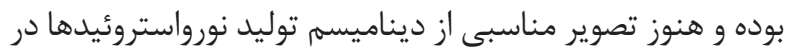
مغز انسان در مراحل مختلف تكامل در دست نيست

در حال حاضر مطالعات high throughput روى مغز انسان با توريا

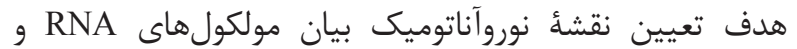

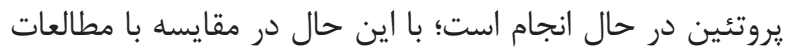

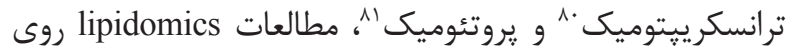

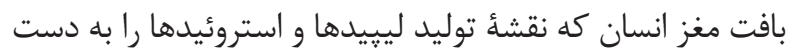

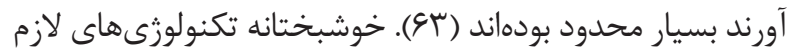

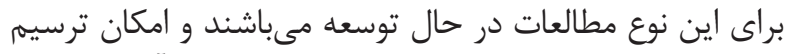

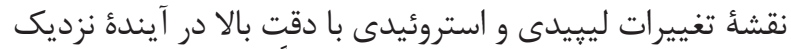

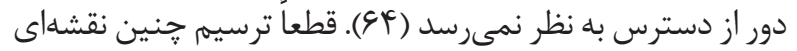

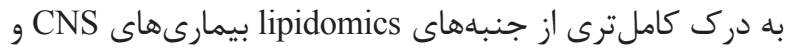
ايجاد رويكردهاى درمانى جديد كمكى شايدائى خواهد نمود.

1. Le Goascogne C, Robe P, Gouézou M, Sananès N, Baulieu EE, Waterman M. Neurosteroids: cytochrome P-450scc in rat brain. Science. 1987; 237(4819): 1212-5.

2. Hu ZY, Bourreau E, Jung-Testas I, Robel P, Baulieu EE. Neurosteroids: oligodendrocyte mitochondria convert cholesterol to pregnenolone. Proc Natl Acad Sci USA. 1987; 84(23): 8215-9.

3. Jung-Testas I, Hu ZY, Baulieu EE, Robel P. Neurosteroids: biosynthesis of pregnenolone and progesterone in primary cultures of rat glial cells. Endocrinology. 1989; 125(4): 2083-91.

4. Puia G, Santi MR, Vicini S, Pritchett DB, Purdy RH, Paul SM. et al. Neurosteroids act on recombinant human GABAA receptors. Neuron. 1990; 4(5): 759-65.

5. Majewska MD, Demirgören S, Spivak CE, London

\footnotetext{
${ }^{75}$ Dysarthria

${ }^{76}$ Dysphagia

${ }^{77}$ Dystonia

${ }^{78}$ Niemann-Pick type C
}

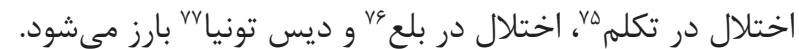

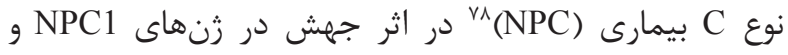

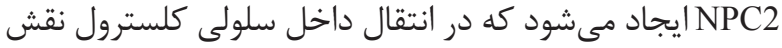

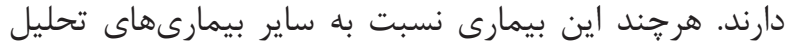

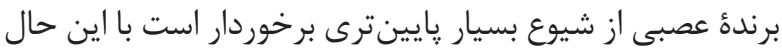

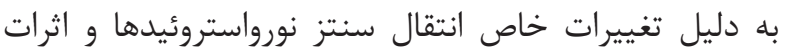

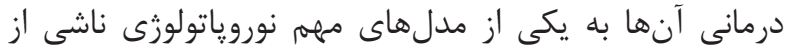

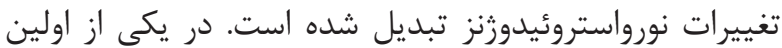

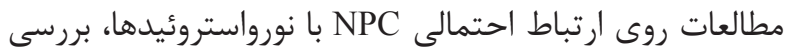

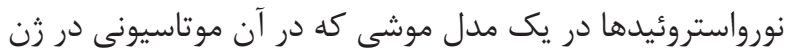

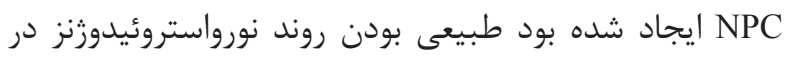

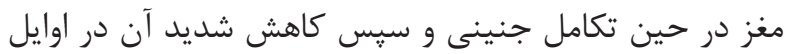
دورة نوزادى و قبل از آغاز علايم نورولوزيك رانين رانشان داد.

5-alpha P450SCC از دست رفتن نورونهاى بيانكندائ

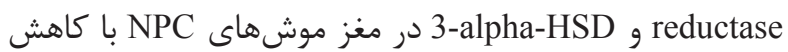

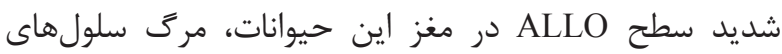

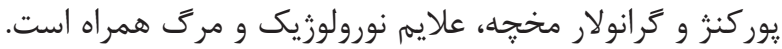

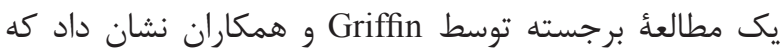

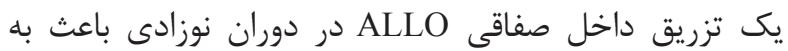

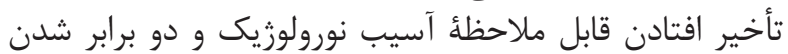

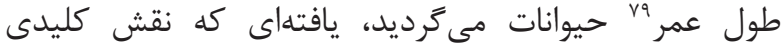

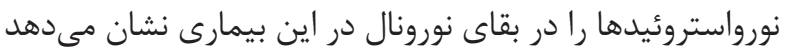

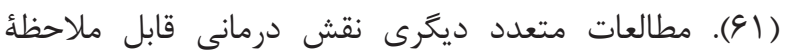

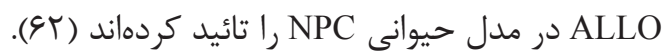

منابع

ED. The neurosteroid dehydroepiandrosterone sulfate is an allosteric antagonist of the GABAA receptor. Brain Res. 1990; 526(1): 143-6.

6. Belelli D, Lambert JJ. Neurosteroids: endogenous regulators of the GABA(A) receptor. Nat Rev Neurosci. 2005; 6: 565-75.

7. Mellon SH, Griffin LD. Neurosteroids: biochemistry and clinical significance. Trends Endocrinol Metab. 2002; 13(1): 35-43.

8. Agís-Balboa RC, Pinna G, Zhubi A, Maloku E, Veldic $\mathrm{M}$, Costa $\mathrm{E}$, et al. Characterization of brain neurons that express enzymes mediating neurosteroid biosynthesis. Proc Natl Acad Sci USA. 2006; 103(39): 14602-7.

9. Mellon SH, Deschepper CF. Neurosteroid biosynthesis: genes for adrenal steroidogenic enzymes are expressed in

\footnotetext{
${ }^{79}$ Life span

${ }^{80}$ Transcriptomics

${ }^{81}$ Proteomics
} 
the brain. Brain Res. 1993; 629(2): 283-92.

10. Kohchi C, Ukena K, Tsutsui K. Age-and regionspecific expressions of the messenger RNAs encoding for steroidogenic enzymes p450scc, P450c17 and 3betaHSD in the postnatal rat brain. Brain Res. 1998; 801(12): 233-8.

11. Sanne JL, Krueger KE. Expression of cytochrome P450 side-chain cleavage enzyme and 3 betahydroxysteroid dehydrogenase in the rat central nervous system: a study by polymerase chain reaction and in situ hybridization. J Neurochem. 1995; 65(2): 528-36.

12. Aste N, Watanabe Y, Shimada K, Saito N. Sex-and age-related variation in neurosteroidogenic enzyme mRNA levels during quail embryonic development. Brain Res. 2008; 1201: 15-22.

13. Tsutsui K, Ukena K, Usui M, Sakamoto H, Takase M. Novel brain function: biosynthesis and actions of neurosteroids in neurons. Neurosci Res. 2000; 36(4): 261-73.

14. Reddy DS. Neurosteroids: endogenous role in the human brain and therapeutic potentials. Prog Brain Res. 2010; 186: 113-37.

15. Roberts E, Bologa L, Flood JF, Smith GE. Effects of dehydroepiandrosterone and its sulfate on brain tissue in culture and on memory in mice. Brain Res. 1987; 406: 357-62.

16. Flood JF, Smith GE, Roberts E. Dehydroepiandrosterone and its sulfate enhance memory retention in mice. Brain Res. 1988; 447(2): 269-78.

17. Flood JF, Roberts E. Dehydroepiandrosterone sulfate improves memory in aging mice. Brain Res. 1988; 448(1): 178-81.

18. Flood JF, Morley JE, Roberts E. Pregnenolone sulfate enhances post-training memory processes when injected in very low doses into limbic system structures: the amygdala is by far the most sensitive. Proc Natl Acad Sci USA. 1995; 92(23): 10806-10.

19. Rudman D, Shetty KR, Mattson DE. Plasma dehydroepiandrosterone sulfate in nursing home men. J Am Geriatr Soc. 1990; 38(4): 421-7.

20. Vallée M, Mayo W, Le Moal M. Role of pregnenolone, dehydroepiandrosterone and their sulfate esters on learning and memory in cognitive aging. Brain Res Brain Res Rev. 2001; 37(1-3): 301-12.

21. Smith CC, Gibbs TT, Farb DH. Pregnenolone sulfate as a modulator of synaptic plasticity. Psychopharmacology (Berl). 2014; 231(17): 3537-56.

22. Irwin RP, Maragakis NJ, Rogawski MA, Purdy RH, Farb DH, Paul SM. Pregnenolone sulfate augments NMDA receptor mediated increases in intracellular $\mathrm{Ca} 2+$ in cultured rat hippocampal neurons. Neurosci Lett. 1992; 141(1): 30-4.

23. Mathis C, Paul SM, Crawley JN. The neurosteroid pregnenolone sulfate blocks NMDA antagonistinduced deficits in a passive avoidance memory task. Psychopharmacology (Berl). 1994; 116(2): 201-6.

24. Bergeron R, de-Montigny C, Debonnel G. Potentiation of neuronal NMDA response induced by dehydroepiandrosterone and its suppression by progesterone: effects mediated via sigma receptors. J Neurosci. 1996; 16(3): 1193-202.

25. Wen S, Dong K, Onolfo JP, Vincens M. Treatment with dehydroepiandrosterone sulfate increases NMDA receptors in hippocampus and cortex. Eur J Pharmacol. 2001; 430(2-3): 373-4.

26. Chen L, Miyamoto Y, Furuya K, Dai XN, Mori N, Sokabe M. Chronic DHEAS administration facilitates hippocampal long-term potentiation via an amplification of Src-dependent NMDA receptor signaling. Neuropharmacology. 2006; 51(3): 659-70.

27. Kaasik A, Kalda A, Jaako K, Zharkovsky A. Dehydroepiandrosterone sulphate prevents oxygenglucose deprivation-induced injury in cerebellar granule cell culture. Neurosci. 2001; 102(2): 427-32.

28. Leskiewicz M, Jantas D, Budziszewska B, Lason W. Excitatory neurosteroids attenuate apoptotic and excitotoxic cell death in primary cortical neurons. J Physiol Pharmacol. 2008; 59(3): 457-75.

29. Weaver CE Jr, Wu FS, Gibbs TT, Farb DH. Pregnenolone sulfate exacerbates NMDA-induced death of hippocampal neurons. Brain Res. 1998; 803(1-2): 129-36.

30. Guarneri P, Russo D, Cascio C, De Leo G, Piccoli T, Sciuto V, et al. Pregnenolone sulfate modulates NMDA 


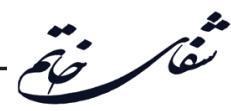

receptors, inducing and potentiating acute excitotoxicity in isolated retina. J Neurosci Res. 1998; 54(6): 787-97.

31. Lockhart EM, Warner DS, Pearlstein RD, Penning DH, Mehrabani S, Boustany RM. Allopregnanolone attenuates N-methyl-D-aspartate-induced excitotoxicity and apoptosis in the human NT2 cell line in culture. Neurosci Lett. 2002; 328(1): 33-6.

32. Djebaili M, Guo Q, Pettus EH, Hoffman SW, Stein DG. The neurosteroids progesterone and allopregnanolone reduce cell death, gliosis, and functional deficits after traumatic brain injury in rats. J Neurotrauma. 2005; 22(1): 106-18.

33. Djebaili M, Hoffman SW, Stein DG. Allopregnanolone and progesterone decrease cell death and cognitive deficits after a contusion of the rat prefrontal cortex. Neuroscience. 2004; 123(2): 349-59.

34. Kruse MS, Rey M, Barutta J, Coirini H. Allopregnanolone effects on astrogliosis induced by hypoxia in organotypic cultures of striatum, hippocampus, and neocortex. Brain Res. 2009; 1303: 1-7.

35. Lapchak PA. The neuroactive steroid 3-alpha-ol-5beta-pregnan-20-one hemisuccinate, a selective NMDA receptor antagonist improves behavioral performance following spinal cord ischemia. Brain Res. 2004; 997(2): 152-8.

36. Afrazi S, Esmaeili-Mahani S, Sheibani V, Abbasnejad M. Neurosteroid allopregnanolone attenuates high glucose-induced apoptosis and prevents experimental diabetic neuropathic pain: in vitro and in vivo studies. J Steroid Biochem Mol Biol. 2014; 139: 98-103.

37. Charalampopoulos I, Remboutsika E, Margioris AN, Gravanis A. Neurosteroids as modulators of neurogenesis and neuronal survival. Trends Endocrinol Metab. 2008; 19(8): 300-7.

38. Jung-Testas I, Schumacher M, Robel P, Baulieu EE. The neurosteroid progesterone increases the expression of myelin proteins (MBP and CNPase) in rat oligodendrocytes in primary culture. Cell Mol Neurobiol. 1996; 16(3): 439-43.

39. Baulieu E, Schumacher M. Progesterone as a neuroactive neurosteroid, with special reference to the effect of progesterone on myelination. Steroids. 2000; 65(10-11): 605-12.
40. Ghoumari AM, Ibanez C, El-Etr M, Leclerc P, Eychenne B, O'Malley BW, et al. Progesterone and its metabolites increase myelin basic protein expression in organotypic slice cultures of rat cerebellum. J Neurochem. 2003; 86(4): 848-59.

41. Noorbakhsh F, Ellestad KK, Maingat F, Warren KG, Han MH, Steinman L, et al. Impaired neurosteroid synthesis in multiple sclerosis. Brain. 2011; 134: 270321.

42. Paul AM, Branton WG, Walsh JG, Polyak MJ, Lu JQ, Baker GB, et al. GABA transport and neuroinflammation are coupled in multiple sclerosis: regulation of the GABA transporter-2 by ganaxolone. Neuroscience. 2014; 273: 24-38.

43. Noorbakhsh F, Baker GB, Power C. Allopregnanolone and neuroinflammation: a focus on multiple sclerosis. Front Cell Neurosci. 2014; 8: 134. doi: 10.3389/ fncel.2014.00134.

44. Weill-Engerer S, David JP, Sazdovitch V, Liere P, Eychenne B, Pianos A, et al. Neurosteroid quantification in human brain regions: comparison between Alzheimer's and nondemented patients. J Clin Endocrinol Metab. 2002; 87(11): 5138-43.

45. Kim SB, Hill M, Kwak YT, Hampl R, Jo DH, Morfin R. Neurosteroids: Cerebrospinal fluid levels for Alzheimer's disease and vascular dementia diagnostics. J Clin Endocrinol Metab. 2003; 88(11): 5199-206.

46. Naylor JC, Kilts JD, Hulette CM, Steffens DC, Blazer DG, Ervin JF, et al. Author information Allopregnanolone levels are reduced in temporal cortex in patients with Alzheimer's disease compared to cognitively intact control subjects. Biochim Biophys Acta. 2010; 1801(8): 951-9.

47. Marx CE, Trost WT, Shampine LJ, Stevens RD, Hulette CM, Steffens DC, et al. The neurosteroid allopregnanolone is reduced in prefrontal cortex in Alzheimer's disease. Biol Psychiatry. 2006; 60(12): 1287-94.

48. Smith CD, Wekstein DR, Markesbery WR, Frye CA. 3alpha,5alpha-THP: a potential plasma neurosteroid biomarker in Alzheimer's disease and perhaps nonAlzheimer's dementia. Psychopharmacology (Berl). 2006; 186(3): 481-5.

49. Singh C, Liu L, Wang JM, Irwin RW, Yao J, Chen 
$\mathrm{S}$, et al. Allopregnanolone restores hippocampaldependent learning and memory and neural progenitor survival in aging 3xTgAD and nonTg mice. Neurobiol Aging. 2012; 33(8): 1493-506.

50. Qian X, Cao H, Ma Q, Wang Q, He W, Qin P, et al. Allopregnanolone attenuates a beta 25-35-induced neurotoxicity in PC12 cells by reducing oxidative stress. Int J Clin Exp Med. 2015; 8(8): 13610-5.

51. Bengtsson SK, Johansson M, Bäckström T. Longterm continuous allopregnanolone elevation causes memory decline and hippocampus shrinkage, in female wild-type B6 mice. Horm Behav. 2015; 78: 160-7.

52. Bengtsson SK, Johansson M, Bäckström T, Wang M. Chronic allopregnanolone treatment accelerates Alzheimer's disease development in $\mathrm{A} \beta \mathrm{PP}(\mathrm{Swe})$ PSEN1(AE9) mice. J Alzheimers Dis. 2012; 31(1): 71-84

53. Xu B, Yang R, Chang F, Chen L, Xie G, Sokabe M, et al. Neurosteroid PREGS protects neurite growth and survival of newborn neurons in the hippocampal dentate gyrus of APPswe/PS1dE9 mice. Curr Alzheimer Res. 2012; 9(3): 361-72.

54. Li L, Xu B, Zhu Y, Chen L, Sokabe M, Chen L. DHEA prevents Abeta25-35-impaired survival of newborn neurons in the dentate gyrus through a modulation of PI3K-Akt-mTOR signaling. Neuropharmacology. 2010; 59(4-5): 323-33.

55. di-Michele F, Luchetti S, Bernardi G, Romeo E, Longone P. Neurosteroid and neurotransmitter alterations in Parkinson's disease. Front Neuroendocrinol. 2013; 34(2): 132-42.

56. di-Michele F, Longone P, Romeo E, Lucchetti S, Brusa L, Pierantozzi M, et al. Decreased plasma and cerebrospinal fluid content of neuroactive steroids in Parkinson's disease. Neurol Sci. 2003; 24(3): 172-3.

57. Luchetti S, Bossers K, Frajese GV, Swaab DF.
Neurosteroid biosynthetic pathway changes in substantia nigra and caudate nucleus in Parkinson's disease. Brain Pathol. 2010; 20(5): 945-51.

58. Melcangi RC, Caruso D, Levandis G, Abbiati F, Armentero MT, Blandini F. Modifications of neuroactive steroid levels in an experimental model of nigrostriatal degeneration: potential relevance to the pathophysiology of Parkinson's disease. J Mol Neurosci. 2012; 46(1): 177-83.

59. Adeosun SO, Hou X, Jiao Y, Zheng B, Henry S, Hill R, et al. Allopregnanolone reinstates tyrosine hydroxylase immunoreactive neurons and motor performance in an MPTP-lesioned mouse model of Parkinson's disease. PLoS One. 2012; 7(11):e50040. doi:10.1371/journal. pone. 0050040 .

60. Wang JM, Irwin RW, Liu L, Chen S, Brinton RD. Regeneration in a degenerating brain: potential of allopregnanolone as a neuroregenerative agent. Curr Alzheimer Res. 2007; 4(5): 510-7.

61. Griffin LD, Gong W, Verot L, Mellon SH. Niemann-Pick type $\mathrm{C}$ disease involves disrupted neurosteroidogenesis and responds to allopregnanolone. Nat Med. 2004; 10(7): 704-11.

62. Liao G, Cheung S, Galeano J, Ji AX, Qin Q, Bi $\mathrm{X}$. Allopregnanolone treatment delays cholesterol accumulation and reduces autophagic/lysosomal dysfunction and inflammation in Npc1-/- mouse brain. Brain Res. 2009; 1270: 140-51.

63. Naudí A, Cabré R, Jové M, Ayala V, Gonzalo H, Portero-Otín M, et al. Lipidomics of human brain aging and Alzheimer's disease pathology. Int Rev Neurobiol. 2015; 122: 133-89.

64. Wang M, Han X. Advanced shotgun lipidomics for characterization of altered lipid patterns in neurodegenerative diseases and brain injury. Methods Mol Biol. 2016; 1303: 405-22. 